\title{
MORAR NO PATRIMÔNIO
}

ENEIDA DE ALMEIDA UNIVERSIDADE SÃO JUDAS TADEU, SÃO PAULO, SÃO PAULO, BRASIL Arquiteta e doutora pela FAU-USP (2010), Mestre pela Università La Sapienza de Roma (1987), é professora da Graduação e Pós-Graduação em Arquitetura e Urbanismo da Universidade São Judas Tadeu, São Paulo. Coordenou a mesa-redonda "Morar no patrimônio" que integrou o Seminário Habitação como patrimônio cultural promovido em 2016 pelo Centro de Preservação Cultural da USP (CPC-USP).

\section{DOI}

http://dx.doi.org/10.11606/issn.1980-4466.v0iesp22p255-270 


\section{MORAR NO PATRIMÔNIO}

ENEIDA DE ALMEIDA

\section{RESUMO}

Este texto sintetiza e comenta a troca de experiências entre moradores de três casas reconhecidas como patrimônio cultural: Doris Lenate, da Vila Maria Zélia; Boris Fausto, falando de sua própria residência, projetada por Sergio Ferro; e Beatriz Millan, apresentando a casa Roberto Millan, projetada por Carlos Millan. José Cazarin, diretor da Imobiliária Axpe, contribui para o debate com a exposição de seu trabalho de comercialização de bens culturais.

\section{PALAVRAS-CHAVE}

Casas paulistas. Edifícios residenciais. Patrimônio ambiental urbano. 


\section{LIVING IN HERITAGE}

ENEIDA DE ALMEIDA

\section{ABSTRACT}

This paper synthesizes and comments on the exchange of experiences between residents of three houses recognized as cultural heritage: Doris Lenate of Vila Maria Zelia, Boris Fausto, speaking of his own residence, designed by Sergio Ferro and Beatriz Millan, with the house Roberto Millan, designed by Carlos Millan. José Cazarin, Axpe's director, contributes to the debate with the exposure of your marketing work of cultural heritages.

\section{KEYWORDS}

São Paulo houses. Residential buildings. Urban environment heritage. 


\section{INTRODUÇÃO}

Toda ação de preservação associada à ideia de patrimônio tem início no reconhecimento de que os artefatos produzidos pelo homem se caracterizam por um valor cultural. É justamente esse reconhecimento que legitima e condiciona as práticas aptas a assegurar a permanência do bem cultural, a impedir seu desaparecimento ou sua descaracterização. A casa unifamiliar e a indústria, da mesma forma que o conjunto de casas operárias e as edificações associadas aos processos iniciais de industrialização, passaram ao largo dos primeiros inventários na Europa do século XIX, quando se disseminaram os debates acerca do tema da preservação e a noção de patrimônio era associada ao "monumento histórico", às edificações de caráter excepcional, a critérios de seleção pautados pelas noções de raridade e antiguidade, que deixavam à margem não apenas a produção trivial que compunha a maior parte da trama das cidades, mas o próprio tecido urbano, a relação entre o "monumento" e o contexto em que este estava inserido. Passaram também ao largo dos primeiros inventários nacionais do Serviço de Patrimônio Histórico Nacional (SPHAN) as edificações que não se enquadravam nos parâmetros de uma configuração de identidade nacional oficial, fundados em uma construção historiográfica em grande medida mitificadora, como foi, por exemplo, a consagração da "casa bandeirista", em concomitância com a exaltação do caráter desbravador do paulista, fenômeno reexaminado por Lia Mayumi neste seminário. 
Casa e indústria passam, portanto, a ser tipologias reconhecidas como patrimônio cultural com interesse de preservação somente a partir do alargamento dessa compreensão, em consonância com a difusão das proposições da micro-história, das narrativas do cotidiano, uma experiência que se torna recorrente quando o homem comum passa a ser admitido como narrador. Nesta mesa deu-se voz, de um lado, a uma habitante da casa operária associada à produção popular, ao universo do trabalho e do trabalhador. De outro, a dois habitantes de casas modernas não necessariamente identificadas com o senso comum de patrimônio, usualmente associado às formas e tipologias tradicionais. Ao relato daqueles que vivem em bens culturais, agregou-se a contribuição de um agente imobiliário que inclui em sua carteira de clientes os proprietários de bens tombados.

Esta mesa desfruta justamente da condição em que o morador define o lugar do discurso e o espaço do seu desenvolvimento. Abrindo um novo campo de discussão, reuniu diferentes depoimentos de residentes e suas respectivas experiências como usuários do espaço doméstico e partícipes do processo de reconhecimento dessas moradias como patrimônio cultural, nem sempre de pleno acordo com as condições que lhes foram impostas pelos órgãos de preservação, muito mais pelo modo como se deram os procedimentos de aplicação, do que propriamente por discordância dos princípios em que se baseiam as disposições legais decorrentes dos processos de tombamento.

\section{DORIS LENATE E A VILA MARIA ZÉLIA}

Iniciou-se o debate com o depoimento de Doris Lenate, psicóloga, integrante da Associação de Moradores da Vila Maria Zélia, uma das vilas operárias mais significativas da cidade, construída pelo industrial Jorge Street, proprietário da Companhia Nacional de Tecidos Juta Belém, no bairro do Belenzinho, entre 1911 e 1917. Conhecida por sua extensão, com mais de cem unidades habitacionais, reunia um conjunto de equipamentos coletivos destinados aos moradores, dentre os quais, escola, creche, farmácia, hospital, armazém e igreja, além de áreas de lazer e equipamentos esportivos.

Doris Lenate teceu considerações sobre o inicial desencontro de informações a respeito do processo de tombamento, o que suscitava dúvidas e confundia os moradores, dificultando a tomada de decisões para 
acompanhar o processo e compreender tanto os direitos concedidos, quanto os deveres a que estavam sujeitos pela legislação de proteção do patrimônio. Mencionou que nem todos tomaram conhecimento do comunicado de tombamento do imóvel, pois não foram endereçadas cartas dos órgãos de preservação a cada morador individualmente, alguns sequer tinham - ou têm ainda hoje - o título de propriedade dos imóveis que ocupam. Informou que há várias unidades pertencentes ao INSS. Comentou a respeito da grande diversidade na composição da população residente, principalmente em função do tempo de moradia, o que caracterizava maior ou menor vínculo das famílias residentes com as pautas coletivas e influenciava diretamente na capacidade de organização. Destacou também a condição diferenciada das moradias quanto ao estado de conservação e quanto às transformações de suas características físicas originais, aspectos que se tornavam mais relevantes em virtude das dificuldades de comunicação com os órgãos de preservação, especialmente em relação aos diferentes níveis de proteção dos imóveis. Foram relatadas ainda as dificuldades econômicas de grande parte das famílias para realizar as obras de manutenção e conservação.

Prevalecia, segundo o relato de Doris, uma sensação de isolamento reforçada pela própria condição de delimitação do território da vila apartado da cidade. Nesse contexto, uma das questões mais sérias a provocar insegurança nos moradores era o fato de esperarem dos órgãos de preservação a indicação de diretrizes e aconselhamentos gerais a respeito do que fazer, que intervenções realizar, e, principalmente, reivindicavam a aceleração de certas aprovações de projetos, como o da recuperação do telhado do Armazém, que suscitava preocupações quanto aos riscos que oferecia à população.

A leitura de um destaque da peça do Ministério Público pela qual ajuizou ação civil em $2012^{1}$, para intimar o poder público a tomar as medidas necessárias à preservação da Vila, permite conhecer os termos em que se manifesta a promotoria. Alega-se que os tombamentos dos órgãos das esferas estadual e municipal não asseguraram a preservação, na medida em que não foram seguidos de ações efetivas para impedir que os bens tombados

\footnotetext{
1. Disponível no site do Ministério Público do Estado de São Paulo. <http://www.mpsp.mp.br/ portal/page/portal/noticias/publicacao_noticias/2012/junho_2012>. Acesso: 30 ago. 2016
} 
continuassem a se degradar e a sofrerem descaracterizações, nem mesmo de outras medidas como a responsabilização dos titulares do domínio dos bens tombados. Solicita-se que a Justiça determine a apuração imediata dos danos encontrados de cada imóvel, a serem indicados em relatórios elaborados pelos dois órgãos, Condephaat e Conpresp, com indicação das medidas técnicas necessárias para a recuperação do conjunto arquitetônico. Dentre as várias medidas recomendadas, há a sugestão um tanto descabida de demolição de edificações descaracterizadas após o tombamento. São ainda estipulados prazos para a entrega dos relatórios e para o início das obras e relativas providências de parcerias a serem celebradas para viabilizar as execuções.

De todos esses problemas relatados, o que suscitou maior preocupação foi justamente essa ação movida pelo Ministério Público. Preponderava um sentimento de injustiça e de incompreensão acerca da atitude dos agentes públicos, pois não lhes parecia cabível serem culpados de terem descaracterizado as tipologias primitivas das casas com as modificações realizadas, na medida em que, pela ótica dos moradores, essas alterações tinham sido feitas com o propósito único de atender às suas necessidades que se transformaram com o passar do tempo. Reclamavam que não tinham tido qualquer orientação preventiva que se antecipasse aos problemas desencadeados após o tombamento e que teriam podido impedir as descaracterizações e as decorrentes punições. A população via-se na condição de vítima de um processo, sem condições econômicas, sem conhecimento específico e sem a orientação técnica para enfrentá-lo.

Doris informou, em uma passagem de seu relato, que nas audiências com representantes do Condephaat e do Conpresp em que esteve presente, após a ação movida pelo Ministério Público, apresentou três solicitações: o estabelecimento de um canal de comunicação com o órgão para sanar as dúvidas com relação às diretrizes de intervenções indispensáveis e demais orientações para aprovação dos projetos; esclarecimentos sobre as características da Vila identificadas pelos técnicos como indispensáveis a se preservar; uma mediação junto ao INSS, em relação aos imóveis de sua propriedade, com o interesse de se discutir a possibilidade de cessão desses ao município.

Como contraponto às dificuldades enfrentadas, Doris Lenate ressaltou 
a importância da organização dos moradores para se posicionarem frente a todo o processo, destacou a decisão de se restaurar a Igreja, e assinalou a relevância das atividades culturais desenvolvidas pelo Grupo XIX de Teatro, estabelecido no local em 2004, a partir de um convênio estabelecido com a Associação Cultural Vila Maria Zélia.

\section{BORIS FAUSTO E SUA CASA (SÉRGIO FERRO, 1961)}

Boris Fausto, historiador, professor aposentado da Faculdade de Filosofia Letras e Ciências Humanas da Universidade de São Paulo, inicia sua fala se solidarizando com Doris Lenate: declara que ficou comovido com a história da moradora, que ali representava os habitantes da Vila Maria Zélia, justamente por sua condição de impotência ao perceber que durante o processo, de um momento a outro, passava de vítima a réu.

Ao falar de sua experiência pessoal, o historiador relembra a decisão de contratar Sérgio Ferro para projetar e construir sua casa como uma grande aventura: ele e a pedagoga, Cynira Stocco Fausto, formavam um jovem casal que se encantou com o discurso do também jovem arquiteto, que lhes foi apresentado por Flávio Império. Menciona a ideia de um projeto revolucionário movido por uma combinação de utopia e ingenuidade. Passados 55 anos daquele momento em que preponderava o entusiasmo pela utopia, a ingenuidade recebe uma ênfase especial. O relato descreve a discrepância entre as intenções do arquiteto e as dificuldades de realização, ligadas ao despreparo da mão de obra, aliado à inexperiência do próprio coordenador dos trabalhos. As pretensões frustradas correspondiam à criação de um canteiro de obras democrático, que pudesse se refletir na qualidade do trabalho executado com simplicidade, rapidez e economia. À medida que o trabalho se desenvolvia, as relações entre os clientes e o arquiteto se desgastavam, não só porque o custo da obra foi maior que o previsto, mas principalmente porque o profissional tendia a desconsiderar a opinião dos moradores, mostrando um perfil autoritário, segundo a fala do historiador. Embora mencione as falhas do processo e a persistência de dificuldades na lida diária com o espaço, ditada pela amplitude e unidade espacial, motivo de certa sensação de desconforto - dificultando a convivência -, o historiador reconhece as qualidades estéticas da arquitetura, o efeito plástico alcançado pela estrutura. Ao comentar esse aspecto, 
relembra a impressão de Haroldo de Campos, amigo da família, assíduo frequentador daquele espaço, que sustentava ser aquela casa na realidade uma escultura.

Os problemas de execução relatados por Boris Fausto em seu depoimento estão presentes no artigo dedicado à residência, publicado na revista Acrópole No 319 (julho/1965), cuja edição documenta a produção de Flávio Império, Rodrigo Lefèvre e Sérgio Ferro. São mencionadas as dificuldades de adaptação da mão de obra às novas técnicas construtivas, $o$ que se refletiu no aumento dos custos inicialmente previstos, assim como a falta de qualidade dos produtos industrializados e os defeitos de fabricação que obrigavam a se fazer contínuos reparos, o que incidiu na extensão do cronograma inicial. Em um texto introdutório de Sérgio Ferro, o arquiteto expressa a relevância da arquitetura de laboratório em que se "ensaiam inúmeras possibilidades técnicas e espaciais, numa atitude de espera e estímulo de transformações sociais profundas".

Um aspecto importante ressaltado na matéria sobre a casa é a relação existente entre o pioneirismo de projetos como esse, que procuravam explorar as possibilidades de aplicação dos avanços industriais na construção civil, e a formação universitária daquela geração, em consonância com as demandas do momento, no sentido de conciliar o progresso técnico com as reivindicações por profundas transformações sociais. A importância do desenho na concepção e execução da obra é também destacada: "A racionalização das técnicas populares e a adaptação do desenho à produção industrial eram necessárias para as prováveis e diferenciadas solicitações”.

Numa observação preliminar, é possível manifestar surpresa diante da constatação de que em plenos anos 1960 o processo de industrialização associado à construção civil fosse tão incipiente, maior perplexidade, porém, nos colhe ao perceber que pouco se avançou com respeito àquela situação. A consulta à Resolução de Tombamento (CONPRESP, 2012) permite compreender os principais motivos da decisão: considera-se a importância da casa, como parte da experiência desenvolvida pelos arquitetos Sérgio Ferro, Rodrigo Lefèvre e Flávio Império entre os anos 1960-70, sua relevante contribuição para a cultura arquitetônica paulista e paulistana, exemplificando o resultado da interação entre as aspirações de certos intelectuais e as propostas pioneiras dos arquitetos. $\mathrm{O}$ 
documento pontua o "interesse arquitetônico-histórico-cultural-social de salvaguardar essa obra para transmiti-la como herança às sociedades futuras". Destaca o caráter de experimentação e inovação dessa casa em relação aos modelos convencionais e informa que as alterações realizadas pelo proprietário "refletem as necessidades de adequação de muitas de suas características ao seu uso continuado e constante, que se alteraram ao longo do tempo e, naturalmente, continuarão a se alterar". Informa que o imóvel constava no Quadro 6 da Zona Especial de Preservação (ZEPEC), prevista no Plano Diretor Estratégico de 2004, condição que lhe conferia desde então o status de bem tombado. As condições específicas da tutela referem-se: ao corpo principal da casa constituído pela estrutura de concreto armado aparente e fechamentos externos, tais como brises móveis de madeira, englobando os fechamentos envidraçados e áreas abertas, constituídas por terraços, o abrigo sob a cobertura principal e os elementos do sistema de captação de águas pluviais, compostos por gárgulas e drenos; ao espaço interno e sua linguagem arquitetônica concisa e austera, articulam o padrão de distribuição das instalações elétricas e hidráulicas. Admite alterações na disposição das divisões internas, desde que se respeite o princípio de concepção original do projeto, de utilização de divisórias leves para atender com flexibilidade às necessidades dos usuários. Por fim, estabelece como área envoltória, sujeita às restrições do tombamento, o limite do próprio lote, autorizando a substituição do volume ocupado atualmente pela edícula situada na divisa, por outro de até dois pavimentos, perfazendo uma altura máxima de sete metros, a partir da cota natural do terreno até o topo da edificação.

A reação do professor em relação ao tombamento, não obstante seu ofício de historiador, não foi de consentimento. Mesmo admitindo que não pudesse ser contra a decisão, declarava sentir-se lesado pelo fato de não tê-lo solicitado, de não ter sido sequer consultado, tendo sabido apenas ao ler o boleto de pagamento do Imposto Predial Territorial Urbano (IPTU). O maior descontentamento do professor diz respeito à ausência de qualquer incentivo para a conservação. Questiona, dessa forma, a eficácia desse instrumento: "em São Paulo, o fato de um imóvel ser tombado não causa uma valorização, mas sim um problema para o proprietário". 


\section{BEATRIZ MILLAN E A CASA ROBERTO MILLAN (CARLOS BARJAS MILLAN, 1960)}

A narrativa de Beatriz Millan, filha de Roberto, para quem a casa tinha sido construída, teve início com a descrição das drásticas transformações do entorno, passados 56 desde sua construção. São indicados os conflitos com a concepção inicial daquela forma de morar, ao mesmo tempo em que evidencia sua condição excepcional na paisagem, fazendo com que a visão externa da casa continue a suscitar o interesse daqueles que se deparam com ela. Foram mencionados os muros altos e o alarme, dentre as principais exigências ligadas aos novos costumes, mais firmemente marcados hoje pela violência urbana e pelo medo, nada comparável com o momento em que a casa foi construída.

Em sua lembrança dos tempos de infância comparece a estrutura sendo montada, seguida da menção honrosa obtida na $6^{\text {a Bienal de São }}$ Paulo (1961), na categoria de habitação unifamiliar. O exercício da memória traz a revelação de que "as crianças amavam muito aqueles espaços, os adultos menos", talvez por obrigá-los a cultivar a convivência, hábito ao que os pequenos se mostravam naturalmente mais inclinados a apreciar, sugere Beatriz Millan. Essa condição do espaço interno concebido como uma obra de arte irretocável, em que o estar se destaca como centro vital ao redor do qual se desenvolvem os demais ambientes, ressaltando o contraste entre a dimensão generosa dessa área, definida como o ponto forte da casa, e a dimensão mínima dos dormitórios, já havia sido assinalada por Boris Fausto ao descrever a própria residência.

Beatriz relembrou ainda que o mobiliário tinha sido todo desenhado pelo arquiteto juntamente com o projeto da casa. O convívio cotidiano com o espaço não diminuiu a intensidade do impacto sensorial provocado pelos elementos que o caracterizam, desde a geometria prismática do corpo suspenso, ao vazio central do interior, marcado pelo jogo de volumes sob a luz, tudo conforme a definição do mestre. Mesmo porque essa condição de arquitetura exemplar é confirmada pelas visitas sempre frequentes de estudantes e pesquisadores, como a fazer ecoar no dia a dia essa dimensão de obra emblemática.

Alejandro Castroviejo e Abilio Guerra, em texto escrito a quatro mãos intitulado Casas brasileiras do século XX, apontam Carlos Millan como um dos precursores da denominada Arquitetura Paulista, "capaz de propor com 
sua estética alternativas aos problemas e práticas inicialmente plantados por Vilanova Artigas em São Paulo e mais distante por Le Corbusier”. Ao analisar a casa, os autores observam a condição de implantação no lote de esquina, em que domina a caixa suspensa do solo por meio de pilotis que acomoda em seu pavimento térreo os ambientes sociais e de serviços, e no pavimento superior os dormitórios (também o de empregados), estúdio e biblioteca. $\mathrm{O}$ programa foi organizado, assinalam os autores, a partir da solução estrutural que estabelece a disposição regular dos oito pilares, aos quais se alinham as vedações que definem os ambientes limítrofes, ao redor de um espaço central de pé-direito duplo que promove a integração entre os pisos superior e inferior. Os dormitórios acoplados aos terraços, configurando uma área de sombreamento e transição entre interior e exterior, são pensados como espaços mínimos, pois de permanência reduzida, uma vez que os amplos espaços de estar é que devem acolher o convívio social, como já havia destacado Beatriz. A estrutura de concreto aparente, de despojada expressão estética, desempenha papel fundamental nos projetos desses anos, reconhecidos sob a denominação de brutalista, como sintetizam os autores:

Pode-se destacar, em sua poética, o apuro formal da caixa suspensa, a racionalidade da estrutura que libera a planta mas coloca-se como expressão secundária, a exploração da plasticidade do concreto através das escadas esculturais que se projetam para fora da volumetria, a ênfase sobre a lógica construtiva, sempre explícita, como um sistema coerente onde se encontram manifestados e expressos os diversos pormenores da construção, mantendo-se sua integridade e funcionalidade sobre qualquer postura mais embelezadora (CASTROVIEJO; GUERRA, 2006).

Jorge Wilheim escreve um artigo publicado na Revista Acrópole № 317 (maio/1965), em que explica tê-lo iniciado na forma de uma carta ao amigo Millan, após o pedido do editor que comentasse as obras do arquiteto a serem publicadas na revista. A ideia da carta ocorreu-lhe pela proximidade do convívio, que o impedia de escrever uma crítica objetiva. Com o desaparecimento prematuro do arquiteto (em dezembro de 1964), o primeiro texto ainda inacabado transformou-se em homenagem e balanço de uma "obra interrompida". A qualidade do seu trabalho é associada por Wilheim à pertinência de uma cultura arquitetônica traduzida em "seu respeito pela verdade construtiva tão típica 
dos melhores exemplos de nossa atual arquitetura". Os principais quesitos e práticas destacados são a simplicidade e beleza do material bruto, a simplificação construtiva e, principalmente, o desejo de racionalizar a construção de acordo com as possibilidades, as perspectivas, a indústria e a mão de obra nacionais. A residência Roberto Millan recebe a seguinte apreciação nesse artigo: "um esplêndido exemplo de programa individual, espaço bem resolvido e método construtivo adequado".

O fato de se tratar de uma habitação que abriga desde sempre a mesma família, por meio da transferência de uma geração a outra, situa esse caso em uma condição particular e fundamentalmente favorável à conservação do imóvel. O processo de tombamento aberto em 2004 ainda não foi concluído² ${ }^{2}$. Uma observação relevante a esse propósito é feita por Mônica Junqueira de Camargo em texto intitulado Residências modernas: patrimônio ameaçado:

Enquanto estiver em posse dessa família, não corre risco de descaracterização, cuidado que deveria ser valorizado pelos órgãos de preservação, que paradoxalmente, só concedem incentivos fiscais a obras que necessitem de intervenção, excluindo aqueles que, por mérito único de seus usuários no zelo e manutenção constantes, chegaram até nossos dias em bom estado de conservação (CAMARGO, 2007).

Se comparado ao depoimento de Boris Fausto, o de Beatriz Millan denota uma convivência mais pacífica, isenta de conflitos em relação ao projeto e à própria casa, provavelmente porque os depoimentos do primeiro incorporam os impasses e desacertos da obra, enquanto que os da segunda, afastados por uma geração, guardam especialmente as boas lembranças da infância e concentram-se na fruição da casa já pronta, não dando ênfase a eventuais tropeços do processo todo. Outra possibilidade é que a construção dessa segunda casa tenha correspondido a um percurso tecnicamente mais controlado e por isso melhor sucedido. Certamente, os dissabores relatados por Boris Fausto provados com o tombamento também devem ter contribuído para o tom de inconformismo de sua fala, o que, de qualquer modo, não encobriu a intensidade do vínculo afetivo estabelecido com a própria casa.

\footnotetext{
2. Em processo de tombamento pelo Conpresp, Resolução 26/04 - APT, de 28/12/04. Imóveis enquadrados ou propostos como ZEPEC pela lei n. 13.885/2004.
} 


\section{JOSÉ CAZARIN E A IMOBILIÁRIA AXPE}

A fala de José Cazarin, diretor da Imobiliária Axpe, trouxe à discussão a reverberação do tombamento na comercialização dos imóveis. Reunindo sócios oriundos do campo da publicidade, a imobiliária manifesta um apelo à “visão diferente do morar", uma atenção estendida aos bens culturais, que eventualmente se enquadrem nessa ótica particular. Seu relato enfatizou a seleção dos imóveis centrada na oposição ao trivial, na "paixão por arquitetura, amor pelo design, devoção à estética". Os atributos de qualidade arquitetônica dos imóveis selecionados para os negócios imobiliários são associados a nomes de reconhecido prestígio no campo da arquitetura.

O discurso do diretor da Axpe despertou interesse na medida em que contrariou o senso comum que associa o tombamento, e a ideia de patrimônio, à desvalorização comercial. Essa redução de valor estaria associada à avaliação de que as restrições às alterações ou reformas, necessariamente submetidas às análises e aprovações dos órgãos competentes, corresponderiam a um inevitável ônus aos proprietários e, consequentemente, desestimulariam investimentos nesses imóveis.

Uma imobiliária que se dispõe a trabalhar com bens tombados - não apenas, pois explora um nicho particular do mercado de imóveis, identificado com a distinção cultural, o status intelectual - tende a contribuir para a valorização comercial desses imóveis. Colabora para desfazer um círculo vicioso que articula valorização cultural com desvalorização econômica. De todo modo, uma associação entre valor comercial e prestígio intelectual determina a seleção exclusiva de imóveis vinculados à produção erudita, ou seja, a que desfruta de relativo consenso no ambiente arquitetônico e cultural, o que não abrange necessariamente a produção popular, anônima, resultante de práticas profissionais corriqueiras.

Desconstruir visões consolidadas pela combinação de vozes que soam simultaneamente produzindo variedade de linguagens e de interpretação de determinadas realidades, foi um dos grandes méritos do seminário confirmado pela composição desta mesa e pela justaposição de suas narrativas.

\section{MESA POSTA}

É crucial o papel exercido pelos técnicos por conta do poder de decisão que detêm, pelo lugar de autoridade que ocupam, pois serão eles a examinar os 
processos e autorizar ou negar os recursos, a deferir ou recusar determinadas alterações no bem tombado quando forem pleiteadas pelos proprietários. Igualmente fundamental a posição dos pesquisadores, responsáveis tanto pela formulação teórica, quanto pela articulação entre conceitos e práticas, pela experimentação, difusão e troca de conhecimento no campo da investigação e da atividade profissional. Inadmissível, no entanto, desmerecer a relevância do ponto de vista do usuário, especialmente na discussão do tema da habitação, um espaço primordialmente ligado à domesticidade, cuja compreensão geral está circunscrita ao âmbito familiar. Indispensável, portanto, promover o diálogo e favorecer a escuta daquele que se vê submetido à legislação na condição de quem sofre a ação e que, por participar do processo visto de dentro, é aquele com reais dificuldades de exercitar um mínimo distanciamento, uma isenção de análise.

Somente ampliando o espaço de discussão entre os diversos atores envolvidos no tema da preservação do patrimônio cultural, é que se conseguirá dirimir qualquer percepção de abuso de poder público por parte de alguns cidadãos que hoje se enxergam na condição de vítimas de um processo que lhes foi injustamente imposto, principalmente por se encontrarem em dificuldades de atender às exigências da legislação e avistarem possibilidades muito reduzidas de exercer uma participação mais efetiva nas decisões oficiais.

Para a plena circulação de ideias e o aprimoramento das práticas entre os vários agentes que atuam nessa área sejam os membros das equipes técnicas dos órgãos de tutela patrimonial, sejam os especialistas que atuam na iniciativa privada, ou aqueles que exercem as atividades de ensino e pesquisa, convém ampliar necessariamente a participação do usuário, direto responsável não somente pelo uso e conservação, mas de fundamental importância para se difundir a apreciação e valoração do bem cultural.

Se a casa é espelho dos que a habitam, dos moradores se espera o maior cuidado possível, o zelo de quem cuida não apenas para si próprios, mas também para a coletividade, cientes da responsabilidade que lhes cabe, uma vez que a ideia de patrimônio excede o direito de propriedade e remete a um pacto social, a um comprometimento com o sentido de lugar compartilhado com comunidade da qual se faz parte.

Do técnico do órgão de preservação, por outro lado, pretende-se 
sempre a isenção e imparcialidade nas decisões do ofício, mas também o máximo esforço no sentido de aperfeiçoar os instrumentos de salvaguarda e as inciativas que ampliem os incentivos aos cidadãos que se dispõem a colaborar com as práticas de conservação.

Parece oportuno concluir este texto sobre a mesa de debates que congregou os que moram no patrimônio recorrendo à metáfora da mesa posta, lugar de convívio e de partilha no interior da casa, muitas vezes local de discussões acaloradas, é, sobretudo, espaço privilegiado de entendimento e confraternização.

\section{REFERÊNCIAS}

CAMARGO, Mônica Junqueira de. Residências modernas: patrimônio ameaçado. Anais do $7^{\circ}$ DOCOMOMO Brasil, outubro de 2007. Disponível em: <http://www.docomomo.org.br/seminario\%207\%2opdfs/o64.pdf>. Acesso: 27 ago. 2016.

CASTROVIEJO, Alessandro; GUERRA, Abilio. Casas brasileiras do século XX. Arquitextos, São Paulo, n. 074.01, ano 07, jul. 2006. Disponível em: <http://www.vitruvius.com.br/revistas/ read/arquitextos/07.074/335>. Acesso: 25 ago. 2016.

Revista Acrópole n. 317, ano 27, maio 1965. Disponível em: <http://www.acropole.fau.usp.br/ edicao/317>. Acesso: 30 ago. 2016.

Revista Acrópole n. 319, ano 27, jul. 1965. Disponível em: <http://www.acropole.fau.usp.br/ edicao/319>. Acesso: 30 ago. 2016. 